\title{
The Spectral Aerosol Extinction Monitoring System (S/EMS): setup, observational products, and comparisons
}

\author{
A. Skupin, A. Ansmann, R. Engelmann, H. Baars, and T. Müller \\ Leibniz Institute for Tropospheric Research TROPOS, Permosserstraße 15, 04318 Leipzig, Germany
}

Correspondence to: A. Skupin (skupin@tropos.de)

Received: 7 August 2013 - Published in Atmos. Meas. Tech. Discuss.: 1 October 2013

Revised: 20 January 2014 - Accepted: 23 January 2014 - Published: 4 March 2014

\begin{abstract}
The Spectral Aerosol Extinction Monitoring System (SÆMS) is presented that allows us to continuously measure the spectral extinction coefficient of atmospheric aerosol particles along an approximately $2.7 \mathrm{~km}$ long optical path at $30-50 \mathrm{~m}$ height above ground in Leipzig $\left(51.3^{\circ} \mathrm{N}, 12.4^{\circ} \mathrm{E}\right)$, Germany. The fully automated instrument measures the ambient aerosol extinction coefficients from 300 to $1000 \mathrm{~nm}$. The main goal of SÆMS observations are long-term studies of the relationship between particle extinction and relative humidity from below $40 \%$ to almost $100 \%$. The setup is presented and observations (a case study and statistical results for 2009) are discussed in terms of time series of $550 \mathrm{~nm}$ particle optical depth, Ångström exponent, and particle size distribution retrieved from the spectrally resolved extinction. The SÆMS measurements are compared with simultaneously performed EARLINET (European Aerosol Research Lidar Network) lidar, AERONET (Aerosol Robotic Network) sun photometer, and in situ aerosol observations of particle size distribution and related extinction coefficients on the roof of our institute. Consistency between the different measurements is found, which corroborates the quality of the SÆMS observations. Statistical results of a period of $1 \mathrm{yr}$ (2009) show mode extinction values of $0.09 \mathrm{~km}^{-1}$ (SÆMS), $0.075 \mathrm{~km}^{-1}$ (AERONET), and $0.03 \mathrm{~km}^{-1}$ (in situ). Ångström exponents for this period are 0.19 (390-880 nm, SFMS) and 1.55 (440-870 nm, AERONET).
\end{abstract}

\section{Introduction}

The interaction of atmospheric aerosol particles with water vapor and the related changes in the particle optical properties has been an important aspect of atmospheric research for decades (Hänel, 1976, 1984; Fitzgerald et al., 1982; Carrico et al., 1998, 2000; McInnes et al., 1998; Gasso et al., 2000; Bundke et al., 2002; Fierz-Schmidhauser et al., 2010; Zieger et al., 2011, 2013). As a function of particle chemical composition, particle age, and state of aerosol mixture, aerosols can show a very different hygroscopic behavior (i.e., water uptake with increasing relative humidity), and thus can have a rather complex impact on the optical properties of the atmosphere. There is a clear need for more field observations of aerosol optical properties as a function of relative humidity from low $(<40 \%)$ to very high values $(>95 \%)$ in order to better describe aerosols in climate models, to better separate aerosols and clouds in satellite remote sensing products, and for a better understanding of aerosol-cloud interaction (Koren et al., 2007, 2009).

Motivated by the need for more aerosol field observations we designed and set up the Spectral Aerosol Extinction Monitoring System (SÆMS). The goal is to monitor the wavelength spectrum of particle extinction coefficients continuously at a height of $30-50 \mathrm{~m}$ above ground throughout all seasons of the year and to simultaneously measure relative humidity and temperature along the aerosol-extinction measurement path. The most interesting days for our study are those with a strong change in relative humidity, e.g., from near $100 \%$ in the early morning to $30-40 \%$ later on during the day, and correspondingly strong changes in the particle extinction coefficient. Besides the humidity effect, air mass transport changes and vertical mixing effects have to be taken into account in the data analysis. Emissions from local sources may also affect the results.

The aim of this first paper on SÆMS is to present the measurement setup and the measurement procedure. A description of the system is given in Sect. 2. In Sect. 3, the 
uncertainty sources are briefly discussed. An overview of the observable products and unique quality assurance efforts (comparisons with photometer, lidar, and in situ measurements) are presented in Sect. 4. A summary is given in Sect. 5.

\section{Instrument, retrieval method, and measurement procedure}

The basic measurement principle of SÆMS is adapted from LP-DOAS (long-path differential optical absorption spectroscopy) (Platt and Perner, 1983; Platt, 1994). Foregoing efforts to develop and apply a DOAS technique at the Leibniz Institute for Tropospheric Research (TROPOS) for aerosol extinction measurements date back to the early 1990s (Flentje et al., 1997). A first test version of our long-path aerosol extinction spectrometer was constructed and successfully tested by Müller et al. (2005).

The steering unit for light transmission and the receiving and detection units are mounted in the roof laboratory of TROPOS $\left(51.3^{\circ} \mathrm{N}, 12.4^{\circ} \mathrm{E} ; 120 \mathrm{~m}\right.$ above sea level). The setup of SÆMS is shown schematically in Fig. 1. Figure 2 shows a sketch of the field site and the arrangement of the SÆMS measurement towers. A broadband $450 \mathrm{~W}$ Xe-arc high-pressure lamp (1 in Fig. 1) is used as radiation source. The lamp is placed in the focus of a coaxial Newtonian telescope (5) which simultaneously emitts and receives the radiation. After passing a pinhole (2), the divergent radiation beam is reflected with a planar mirror (4) on the parabolic telescope reflector (5) with $400 \mathrm{~mm}$ diameter and $2000 \mathrm{~mm}$ focal length. The beam is then sent into the atmosphere via a planar mirror $(6,600 \mathrm{~mm}$ diameter) that is mounted in the astronomical dome of TROPOS (Fig. 2). This mirror can be rotated by $360^{\circ}$ (azimuth) and tilted by $20^{\circ}$ (elevation) in order to find the position for maximum reflection as explained below. The transmitted beam travels through the atmosphere and is returned by one of the reflector arrays mounted at each of the both towers (Fig. 2). During a measurement, the radiation beam is alternately directed to the reference tower and the measurement tower. The two atmospheric paths are shown in detail in Fig. 2. In the current setup, the measurement tower is $2.84 \mathrm{~km}$ northeast of the reference tower, thus the difference in optical path lengths is $5.68 \mathrm{~km}$.

With the mirror (6), the reflected light is again directed to the parabolic mirror (5) and then passed to a further flat mirror (8) towards the detection units. The flat mirrors (4 and 8 ) are arranged such that the cross sections of the transmitted and the detected radiation are ring-like. As a result of the different sizes of the two mirrors (4 and 8), the diameter of the detected intensity ring is somewhat smaller than the one of the transmitted beam. A beam splitter (9) directs light onto a photodiode (13). This large-area photodiode, which is used as reference for the spectrally resolved observation, is equipped with a $550 \mathrm{~nm}$ filter (11) and a lens system $(10,12)$.

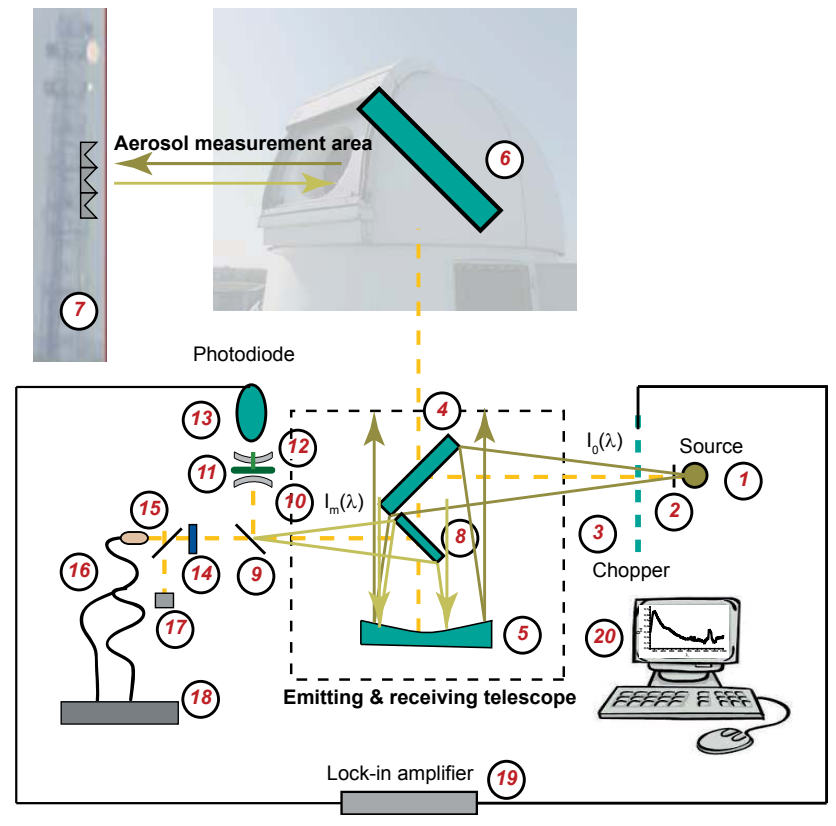

Fig. 1. Setup of SÆMS. (1) High-pressure Xe-arc lamp, (2) entrance pinhole (3) chopper, $(4,8)$ flat mirror, (5) parabolic mirror, (6) adjustment mirror, $(7)$ retroreflector arrays, $(9,15)$ beam splitter, $(10,12)$ lens, (11) filter at $550 \mathrm{~nm}(13)$ photodiode, (14) filter, (16) bifocal optical fiber, (17) CCD camera, (18) spectrometer, (19) lock-in amplifier, and (20) computer. The light (intensity $I_{0}$ ) from source 1 is transmitted into the atmosphere via mirrors 4,5 , and 6 . The light reflected by the retroreflector 7 (intensity $I_{\mathrm{m}}$ in the case of the measurement tower and $I_{\mathrm{r}}$ in the case of the reference tower) is then directed via the mirrors 6,5 , and 8 to the $550 \mathrm{~nm}$ photodiode (13) and the spectrometer (18).

The arrangement (10-13) is also used for the pre-adjustment of the system, i.e., for the precise positioning of the transmitted radiation beam on the retroreflectors. A fraction of the received light is imaged via a beam splitter (15) to a CCD camera (17), which is also used for continuous checking of the quality of the alignment (i.e., the position of the reflected spot on the reflector array).

With the lock-in amplifier (19) and the chopper (3), the light is detected phase-sensitive at the wavelength of $550 \mathrm{~nm}$. The spectral information is obtained with the grating spectrometer (18). A filter (14) in front of the spectrometer suppresses the strong bands of the Xe spectrum. The light is coupled into the spectrometer (Ocean Optics) with a bifocal optical fiber (16). The spectrometer has two channels and measures the intensity in the wavelength range of $300-1000 \mathrm{~nm}$ with $10 \mathrm{~nm}$ resolution.

The emission characteristic of the lamp is not accurately known and the intensity as well as the emitted spectrum may change with time. The short-distance SÆMS measurement is therefore used as a reference measurement, and the atmospheric extinction coefficient is determined by a relative measurement of the radiative fluxes by using the two towers, 

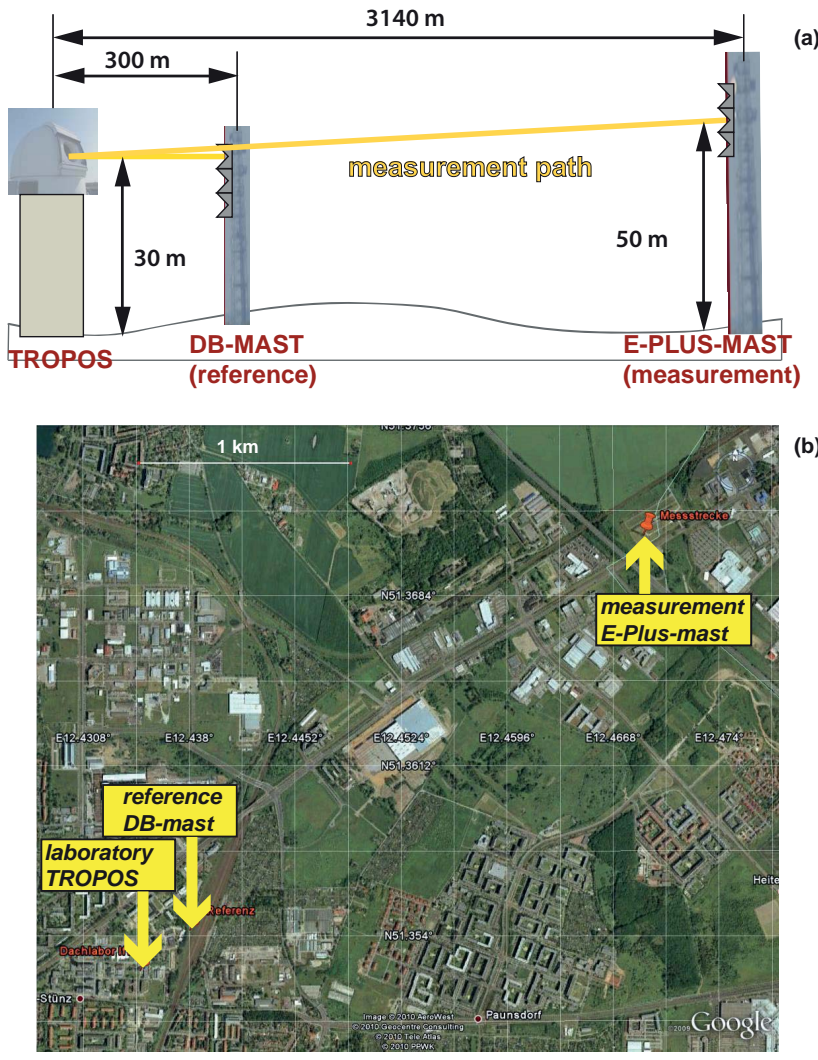

Fig. 2. (a) Sketch of the SÆMS reference and measurement pathes outside of the TROPOS laboratory, and (b) Google Earth image with reference path (reference DB tower) and measurement path (measurement E-Plus tower). The distance between the reference and measurement towers is $2.84 \mathrm{~km}$. The SÆMS field site is about $3 \mathrm{~km}$ northeast of the Leipzig city center. The E-Plus tower is located $250 \mathrm{~m}$ east of a highway (Autobahn A14 from Magdeburg to Dresden).

as illustrated in Fig. 2a. The system-dependent spectral response is eliminated by the division of both measured radiation fluxes. As shown in Fig. 2, the measurement paths are 30 and $50 \mathrm{~m}$ above ground level, respectively. At both towers, temperature and relative-humidity sensors are mounted close to the reflectors and measure these meteorological state parameters continuously.

Following the denotation after Müller et al. (2005), the measured spectral intensities $I_{\mathrm{r}}(\lambda)$ and $I_{\mathrm{m}}(\lambda)$ from the reference and measurement tower are given by

$I_{\mathrm{m}}(\lambda)=I_{0}(\lambda) \eta_{\mathrm{m}} \exp \left[-b_{\mathrm{e}}(\lambda) L_{\mathrm{m}}\right]+I_{\mathrm{m}, \mathrm{B}}(\lambda)$

and

$I_{\mathrm{r}}(\lambda)=I_{0}(\lambda) \eta_{\mathrm{r}} \exp \left[-b_{\mathrm{e}}(\lambda) L_{\mathrm{r}}\right]+I_{\mathrm{r}, \mathrm{B}}(\lambda)$

with the transmitted spectral intensity $I_{0}(\lambda)$ of the Xe-arc high-pressure lamp at wavelength $\lambda$; the dimensionless factors $\eta_{\mathrm{m}}$ and $\eta_{\mathrm{r}}$, describing the specific tower-dependent geometry of the optical system; the optical path lengths $L_{\mathrm{m}}$ and $L_{\mathrm{r}}$ from the TROPOS laboratory to the two towers and back to the SÆMS setup; and the sky-background intensity spectra $I_{\mathrm{m}, \mathrm{B}}(\lambda)$ and $I_{\mathrm{r}, \mathrm{B}}(\lambda)$. The total atmospheric extinction coefficient is defined as

$b_{\mathrm{e}}(\lambda)=b_{\mathrm{p}, \mathrm{e}}(\lambda)+b_{\mathrm{m}, \mathrm{s}}(\lambda)+b_{\mathrm{m}, \mathrm{a}}(\lambda)$,

where $b_{\mathrm{p}, \mathrm{e}}$ is the particle extinction coefficient, $b_{\mathrm{m}, \mathrm{s}}$ denotes the molecular or Rayleigh scattering coefficient, and $b_{\mathrm{m} \text {, a }}$ describes the extinction coefficient due to absorption (by different gas species). The two Eqs. (1) and (2) lead to

$b_{\mathrm{e}}(\lambda)=\frac{\ln \left\{\eta\left[I_{\mathrm{r}}(\lambda)-I_{\mathrm{r}, \mathrm{B}}(\lambda)\right] /\left[I_{\mathrm{m}}(\lambda)-I_{\mathrm{m}, \mathrm{B}}(\lambda)\right]\right\}}{L_{\mathrm{m}}-L_{\mathrm{r}}}$

with the overall instrumental constant $\eta=\eta_{\mathrm{m}} / \eta_{\mathrm{r}}$, assuming that the atmospheric extinction conditions are constant during the entire measurement cycle (measurement with reference and measurement tower). The particle extinction coefficient can be obtained from the total atmospheric extinction coefficient by subtracting Rayleigh scattering and gas absorption contributions, according to Eq. (3). Rayleigh scattering can be accurately determined and corrected by means of continuously measured temperature and pressure values (Bucholtz, 1995). To avoid a sensitive impact of gas absorption, particle extinction is measured at wavelengths with rather low, negligible gas absorption.

The Ångström exponent (Ångström, 1964) is the commonly used parameter to describe the spectral dependence of the extinction coefficient,

$\alpha\left(\lambda_{1}, \lambda_{2}\right)=-\frac{\ln \left[b_{\mathrm{p}, \mathrm{e}}\left(\lambda_{1}\right) / b_{\mathrm{p}, \mathrm{e}}\left(\lambda_{2}\right)\right]}{\ln \left(\lambda_{1} / \lambda_{2}\right)}$.

Figure 3 presents an overview of the measurement procedure as performed continuously in the framework of our long-term monitoring program that we started in 2009. A measurement cycle consists of two parts. During the first half, the reference tower is used. By azimuthal and zenithal scans (illustrated in Fig. 3b) the optimum path of the radiation beam, indicated by a maximum in the measured reflected intensity, is determined first. Afterwards, fine tuning provides a very accurate determination of optimum reflection, as our experience shows. As illustrated in Fig. 3b (bottom), this fine-tuning maximum may even not match the optimum position obtained after the first part of the scanning procedure with low step resolution. A single scanning step corresponds to $30 \mathrm{~cm}$ movement of the light beam at the measurement tower reflector array.

As the next step, a spectral intensity measurement is conducted with the spectrometer, and the $550 \mathrm{~nm}$ intensity is measured with the photodiode in addition. The atmospheric data are stored. The radiation beam is finally moved horizontally by $5^{\circ}$ off the retroreflector, and the measurement of the atmospheric background completes the first part of the measurement cycle. For the second part of one measurement 
(a)

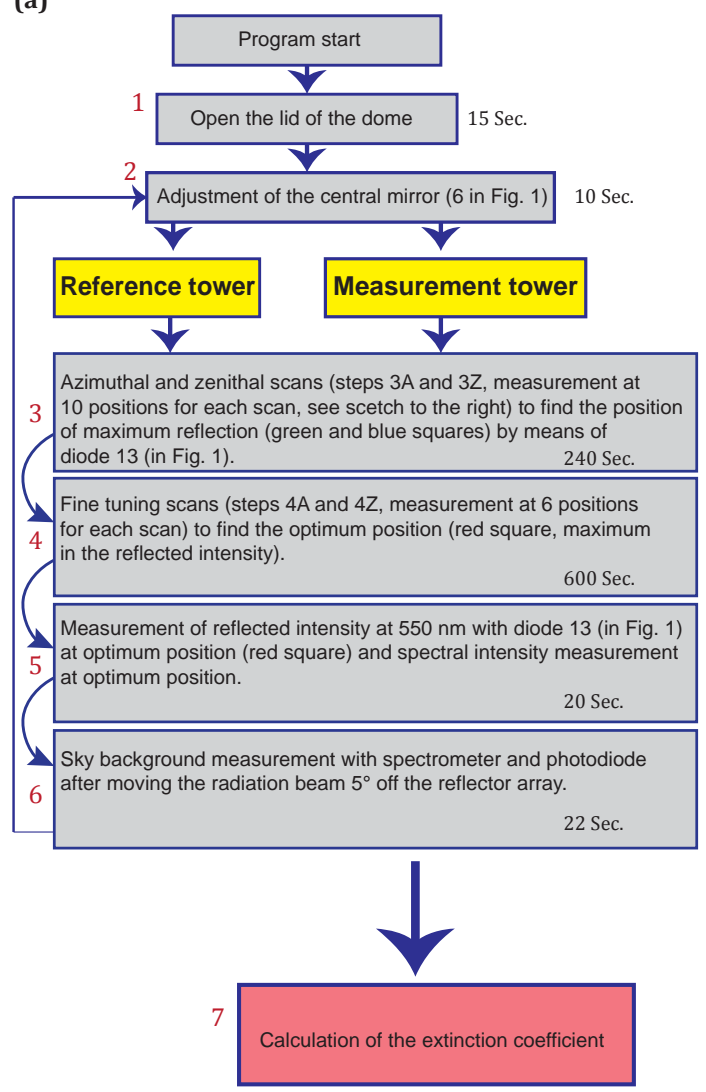

(b)

Zenith angle position

Step $3 Z$

$(550 \mathrm{~nm})$

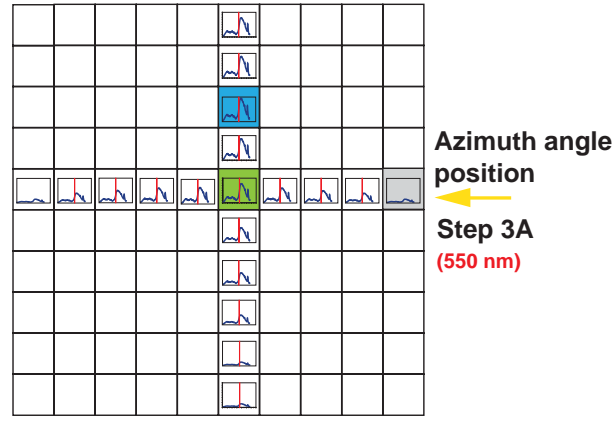

Zenith angle position

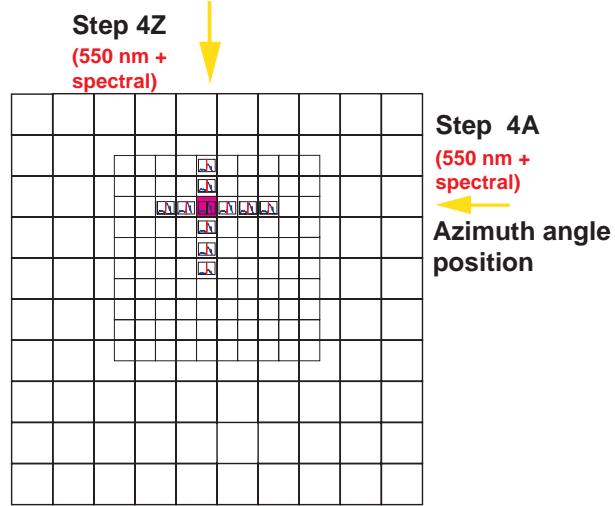

Fig. 3. (a) Flowchart of the measurement procedure. After opening the dome (step 1), the radiation beam is directed towards the retroreflector of the reference tower (step 2). Steps 3-6 are executed for both towers successively. For each tower the procedure takes 15 min. The intensity optimization procedure by moving the mirror positions (steps 3-4) is shown schematically in (b), starting with the adjustment of the azimuth angle (upper panel, gray box). The maximum of the reflected intensity for this scan is highlighted in green. The maximum value during the zenith-angle adjustment is indicated by a blue box. Then the fine tuning with the photodiode is performed (lower panel, optimum position indicated by a red box), followed by the measurement of the spectral intensity with the spectrometer and the $550 \mathrm{~nm}$ diode (step 5). Afterwards the radiation beam is moved horizontally by $5^{\circ}$ (off the reflector, step 6 ) and an atmospheric background measurement is performed. Then the SÆMS radiation beam is directed to the next tower and the procedure (steps 3-6) are conducted again. Finally the spectral extinction coefficient is calculated (step 7).

cycle the beam is direct towards the measurement tower and all scanning and measurement steps are repeated.

A full measurement cycle lasts $1764 \mathrm{~s}$ (about $30 \mathrm{~min}$ ), and each of the tower measurement needs about 15 min $(882 \mathrm{~s})$. The most time-consuming task is a careful adjustment of the radiation beam (see Fig. 3b). As shown in the result section, the time difference of 15 min between the reference and the measurement-tower observations may influence the extinction coefficient retrieval significantly. However, we usually observe a smooth, coherent time series of the particle extinction coefficient, which does not indicate a strong impact of aerosol variability on the retrieval product.

The SÆMS computer software also controls the optimum measurement integration time, which can differ significantly for the two towers. The measurement time is, for example, much larger (on the order of a factor of 1.5-5) under almost foggy conditions (at almost $100 \%$ relative humidity). In this case the amount of reflected radiation is extremely low.

\section{Sources of uncertainties}

Several sources of uncertainty affect the accuracy of the atmospheric extinction measurement. The most relevant sources are discussed here and are related to temporal changes in the particle extinction condition, differences in the surface properties (aerosol sources) along the short and the long optical path, atmospheric turbulence, signal noise, uncertainty in the SÆMS system constant $\eta$, and adjustment errors. 


\subsection{Temporal changes of particle extinction}

According to Eq. (4), the particle extinction retrieval assumes constant atmospheric extinction conditions during an entire measurement cycle of $30 \mathrm{~min}$ (at least $16 \mathrm{~min}$ of this in which the atmospheric extinction measurements are performed). This assumption is violated when short-term changes in the airflow (aerosol advection), relative humidity, aerosol emissions, and aerosol transport occur and lead to significant changes in the aerosol extinction characteristics between TROPOS and the reference tower. Changing sky background conditions on days with cumulus convection and broken cloud fields may also introduce significant uncertainty. As a result of a variable sky background, the determined background intensity may be too high or too low with respect to the intensity recorded during a tower measurement from which the background intensities are then subtracted according to Eq. (4). From our data analysis we estimate that the uncertainty is on the order $5 \%$ with respect to the derived particle extinction coefficient.

\subsection{Inhomogeneous aerosol characteristics at the surface}

The analysis is based on spatially homogeneous aerosol conditions along both optical paths. Homogeneity is especially required for the two optical paths up to the distance of the reference tower. This assumption is almost fulfilled according to Fig. 2. However, there are slight differences in terms of numbers of streets and intensity of traffic along both optical paths up to the reference tower. The contribution to particle extinction uncertainty is less than $5 \%$.

\subsection{Atmospheric turbulence}

Fluctuations in the refractive index of air because of atmospheric turbulence creates random changes in the light-path direction and thus the beam position at the reflection arrays varies during a measurement. Signal variations therefore occur. Such errors are considered in detail in Müller (2001). These random errors can in turn be reduced by averaging over several measurements that are realized within the current measurement cycle of SÆMS. On average these errors are on the order of $0.01 \mathrm{~km}^{-1}$ for the extinction coefficient, or about $10 \%$ in terms of relative uncertainty.

\subsection{Intensity fluctuations of the light source}

Similar effects as introduced by turbulence are caused by intensity fluctuations of the Xe-arc lamp. Respective errors are also reduced by averaging of several measurements. It could be noted that the lamp current also influences the lightintensity fluctuations. The current was set to a value of $18 \mathrm{~A}$ in our case (lamp type UXL-451-O, Ushio) at which these fluctuations are minimal. The impact on the overall uncertainty is estimated to be below $5 \%$.

\subsection{Signal noise}

With increasing atmospheric extinction (decreasing visibility) the signal-to-noise ratio decreases, which is especially the case during times with very high relative humidity. For SÆMS with an optical measurement path length of $5.84 \mathrm{~km}$, our measurements are restricted to conditions with atmospheric extinction coefficients $<1 \mathrm{~km}^{-1}$. Signal noise uncertainties are estimated to be less than $5 \%$ at these cases of high extinction coefficients.

\subsection{Uncertainty of the system constant}

The determination of the system constant $\eta$ is described by Müller (2001) and Lee et al. (2005). The empirical Koschmieder formula, which links the extinction coefficient $b_{\mathrm{e}}(\lambda)$ to the visibility $V$ at $550 \mathrm{~nm}$ wavelength (Koschmieder, $1924)$ according to $V=3.91 / b_{\mathrm{e}}$ is used in this effort. Considering this $V-b_{\mathrm{e}}$ relationship in Eq. (4) and neglecting the sky background influence (to keep the explanation simple) leads to

$\eta=\frac{I_{\mathrm{m}}(\lambda)}{I_{\mathrm{r}}(\lambda)} \exp \left[3.91 V\left(L_{\mathrm{m}}-L_{\mathrm{r}}\right)\right]$.

The system constant $\eta$ is ideally determined on days with high visibility. At our site, we observed visibilities up to $\approx 70 \mathrm{~km}$. Remaining calibration errors are related to the uncertainty of the visibility estimate. Because high visibilities of $>50 \mathrm{~km}$ seldom occur, many $\kappa$ estimates rely on retrievals at lower visibility. The relative uncertainty is estimated to be on the order of $5 \%$.

\subsection{Adjustment errors}

Adjustment uncertainties in the automatic adjustment cycle arise from bad coupling of the reflected intensity signal into the optical fibers. However, measurements at these conditions are usually easily identified by a low signal-to-noise ratio. The error contribution is thus less than $5 \%$.

\subsection{S/EMS overall error estimation}

According to the law of error propagation, these seven error sources lead to an overall relative error of about $15 \%$. These $15 \%$ are considered in the figures of the next section as error bars of the SÆMS particle extinction coefficients.

\section{Observational products and comparisons}

We present the observational products of SÆMS in the framework of an extended case study and in the form of statistical results for the year 2009. Extensive comparisons were performed at TROPOS in 2009 and 2010 with the unique aerosol-monitoring infrastructure at the institute in Leipzig. The quality-assurance efforts include comparisons of the SÆMS retrievals with routine in situ aerosol 
observations, AERONET (Aerosol Robotic Network) sunphotometer measurements, and multiwavelength lidar profiles of particle optical properties performed in the framework of the EARLINET (European Aerosol Research Lidar Network) project.

We begin with the presentation of the observations with a typical measurement example shown in Fig. 4. The measured atmospheric extinction spectrum together with the $550 \mathrm{~nm}$ extinction value measured with the photodiode is given. Rayleigh scattering contributions are strong in the shortwavelength range, and gas absorption by water vapor and oxygen is strong at wavelengths around $700 \mathrm{~nm}$ and larger. The particle extinction coefficient is thus determined in the valleys of the atmospheric extinction spectrum, between the absorption features where gas absorption is practically negligible. In the following the presented SÆMS results are based on the particle extinction coefficients, shown as black dots in Fig. 4.

\subsection{Case study of 3 May 2009}

On 3 May 2009 favorable conditions for extended comparisons between SÆMS and accompanying measurements were given. Almost cloudless conditions allowed for continuous lidar and photometer observations as shown in Fig. 5. Before 08:00 UTC, planetary boundary-layer (PBL) top height was $500-600 \mathrm{~m}$. The lidar observations in the top panel indicate the top of the PBL at about $800 \mathrm{~m}$ (09:00 UTC) and between 1000 and $2000 \mathrm{~m}$ from 09:30 to 11:00 UTC. From 11:00 to 15:30 UTC the PBL top remained almost constant around $2 \mathrm{~km}$ height. Above the PBL further aerosol layers were observed. The $500 \mathrm{~nm}$ aerosol optical depth (AOD, central panel) was 0.5-0.6 from 04:00 to 09:00 UTC and about 0.3-0.4 from 12:00 to 15:00 UTC. The slight AOD decrease with time may be partly related to a decrease in relative humidity in the PBL from the morning to the noon hours. Another reason for the higher AOD in the morning may be the contribution of local sources in the city of Leipzig. With increased PBL growth in the afternoon the local aerosol may be distributed over larger areas, and thus the AOD decreases. Values of AOD were transferred in extinction coefficients in case of known PBL or aerosol layer height from lidar measurements or GDAS data.

In the bottom plot of Fig. 5, the SÆMS time series of the $550 \mathrm{~nm}$ particle extinction coefficient is shown together with the estimated vertical mean extinction coefficient for the PBL as derived from the $500 \mathrm{~nm}$ AOD (sun photometer) divided by the PBL depth (lidar, GDAS data) (Baars et al., 2008), and the estimated vertical mean extinction coefficient for the entire aerosol layer reaching $3 \mathrm{~km}$ height. The estimated PBL mean particle extinction coefficients are unrealistically high, with values $\geq 1 \mathrm{~km}^{-1}$, and dropped rapidly to values of 0.15 $0.2 \mathrm{~km}^{-1}$ after 08:00 UTC when the PBL convection started. In contrast, the mean extinction coefficient for the entire $3 \mathrm{~km}$ thick aerosol layer are too low until 10:00 UTC. After

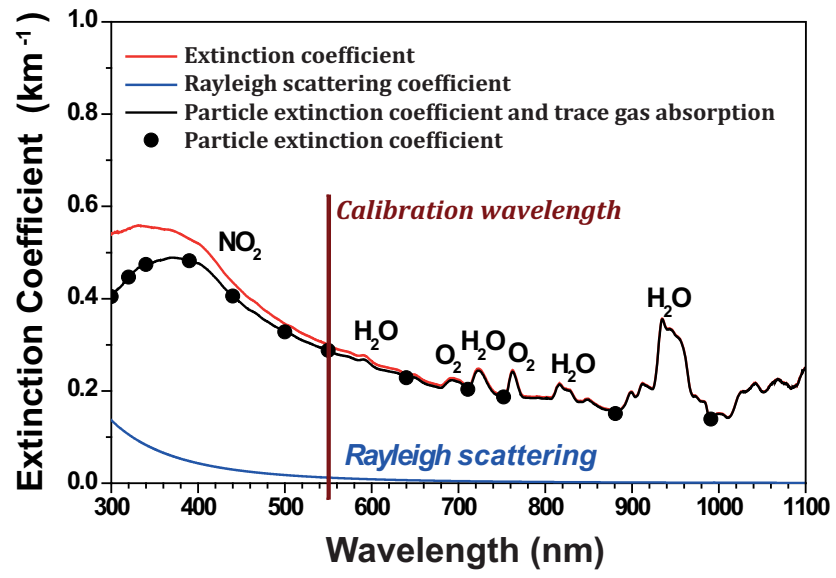

Fig. 4. SÆMS observation of spectral atmospheric extinction (red line), measured spectrum of the extinction coefficient after the correction for Rayleigh scattering (black line), Rayleigh scattering contribution to the measured spectrum (blue line), and particle extinction coefficient (black circles) after corrections for trace gas absorption and Rayleigh scattering.

12:00 UTC, SÆMS and AERONET-derived extinction coefficients are in reasonable agreement. Because relative humidity is lowest close to the surface and steadily increases with height in a well-mixed PBL, on average, the higher relative humidity along the vertical path may be responsible for the slightly higher AERONET extinction values here when compared to the SÆMS values.

With decreasing relative humidity, the particle coefficient at 30-50 m height decreases strongly before 09:00 UTC and thus at times before the onset of the convective PBL evolution. After 09:00 UTC the increasing PBL top height (and thus the increasing air volume available to distribute the urban aerosol pollution over the lower troposphere) contributes to a further decrease of the SÆMS extinction values. The smooth and coherent SÆEMS time series indicates that the method with two independent measurements within $15 \mathrm{~min}$ works well and does not introduce artifacts.

Four-day backward trajectories (HYSPLIT, Hybrid Single-Particle Lagrangian Integrated Trajectory Model) (Draxler and Rolph, 2011) are shown in Fig. 6 to identify the origin of the detected PBL aerosol. The air masses were mainly transported from northeast before noon. At about 18:30 UTC, a strong change in the air mass occurred, indicated by a strong increase in the relative humidity (see Fig. 5, bottom panel). In accordance with the 21:00 UTC backward trajectories, moist air masses have been transported from the west during the evening hours.

The lidar measurements in Fig. 7 provide an overview of the vertical aerosol layering in terms of particle extinction coefficient and Ångström exponent on 3 May 2009, 11:00-13:00 UTC. The respective SÆMS results and the AERONET-photometer-derived Ångström exponent are shown in addition. The SÆMS extinction value at $550 \mathrm{~nm}$ 


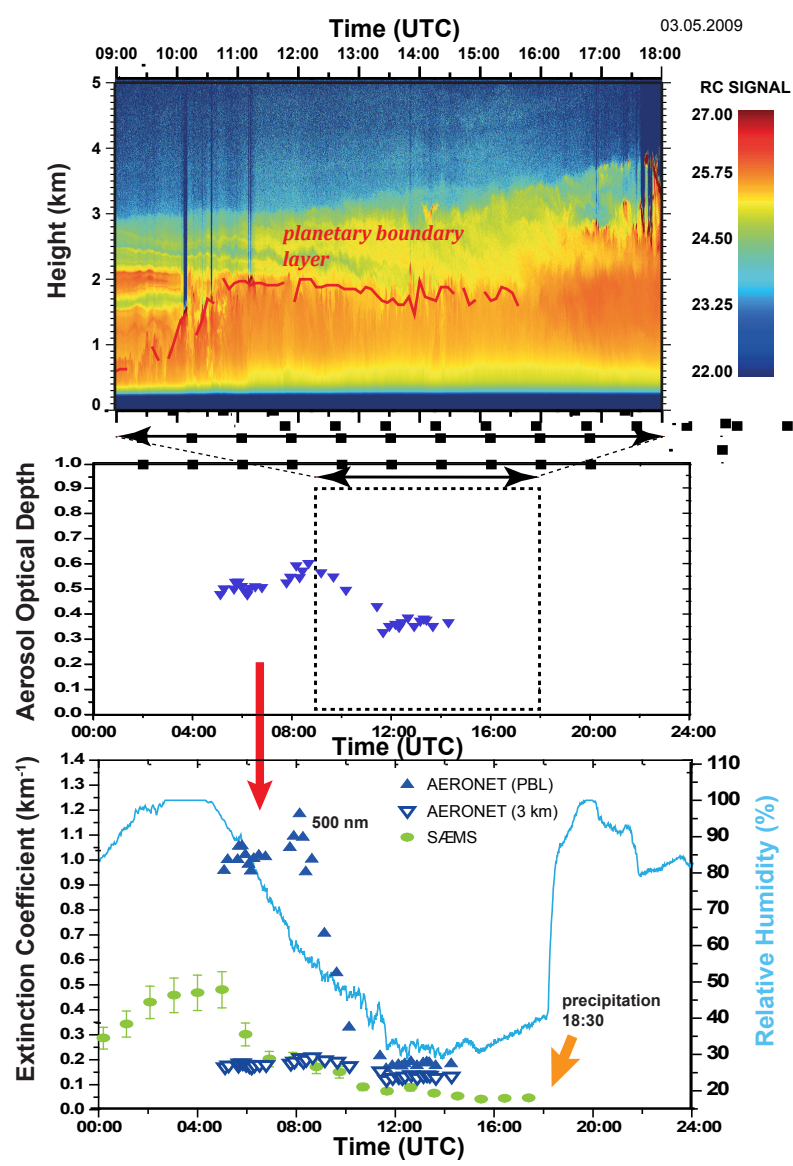

Fig. 5. (Top) Range-corrected $532 \mathrm{~nm}$ backscatter signal measured with lidar on 3 May 2009. The lidar measurement shows the boundary layer (BL) with top height $<1 \mathrm{~km}$ before 09:30 UTC and from 1.7 to $2.0 \mathrm{~km}$ between 12:00 and 16:00 UTC. Free tropospheric aerosol layers reach to $3-4 \mathrm{~km}$ height. (Center) Measured aerosol optical depth (AOD, AERONET) at $500 \mathrm{~nm}$. (Bottom) SÆMS $550 \mathrm{~nm}$ particle extinction coefficient (circles, at $30 \mathrm{~m}$ height) and estimated vertical mean particle extinction coefficient for the boundary layer (filled blue triangles, ratio of AOD to PBL top) and for the entire $3 \mathrm{~km}$ deep tropospheric aerosol layer (open blue triangles). The light-blue line shows the relative humidity measured on the roof of the TROPOS building. At 18:30 UTC a sharp increase in humidity indicates an air-mass change.

agrees well with the lidar observation, and adds a trustworthy extinction value in the near range of the lidar, where the lidar observations are usually no longer trustworthy because of uncertainties in the correction of the overlap effect.

The lidar-derived particle extinction values are obtained from a combined lidar-photometer analysis (see, e.g, Ansmann, 2006) that delivers column extinction-to-backscatter ratios for the lidar wavelengths, accurate backscatter coefficient profiles, and finally also trustworthy estimates of the extinction profiles. The column lidar ratios of $75 \mathrm{sr}(532 \mathrm{~nm})$ and $53 \mathrm{sr}(1064 \mathrm{~nm})$ together with the Ångström exponent of 1.75-2 indicate fresh urban haze dominated by fine-mode

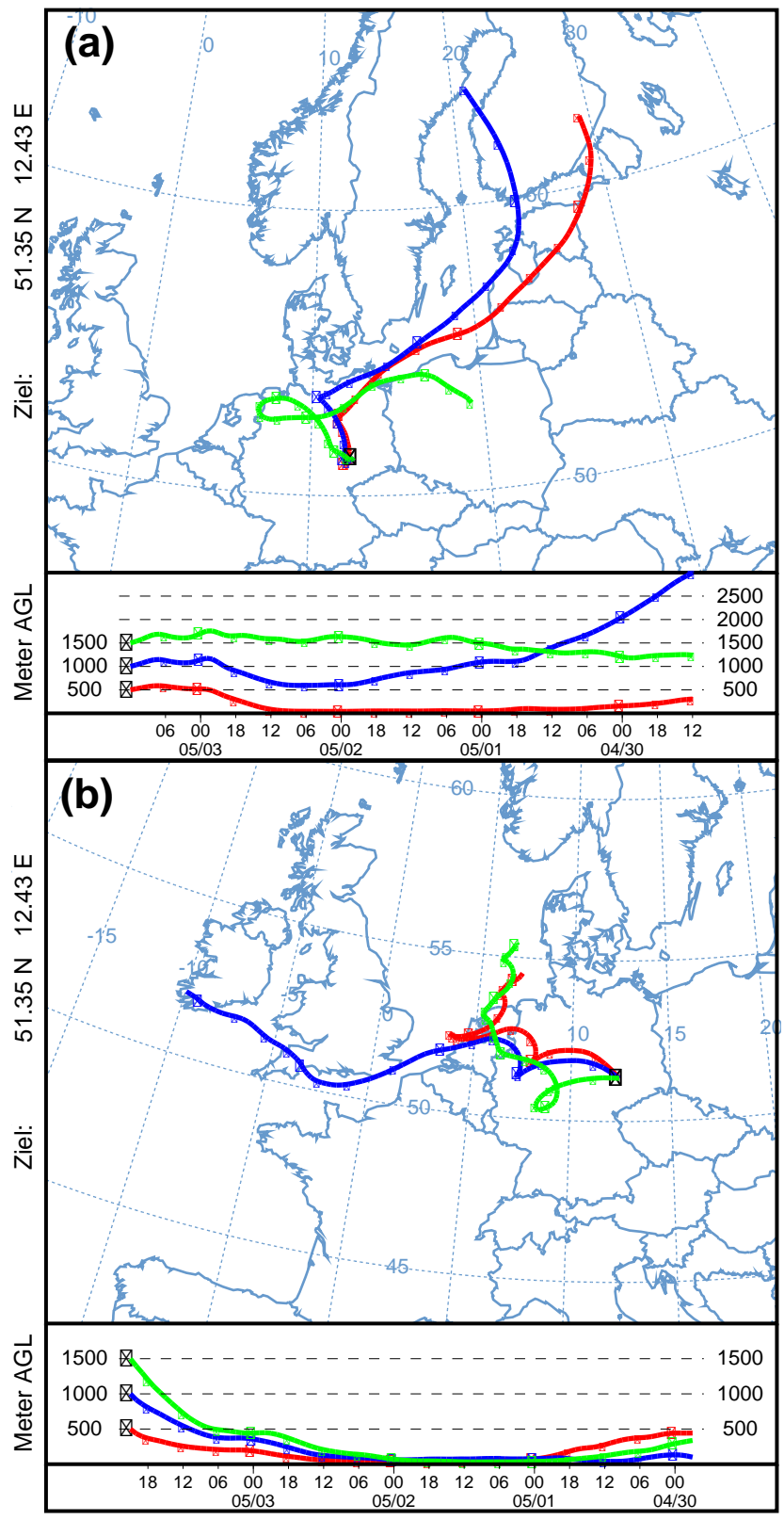

Fig. 6. Four-day backward trajectories (HYSPLIT) arriving at Leipzig on 3 May 2009, 12:00 UTC (a), and 21:00 UTC (b).

particles. The lidar observation also indicates that the lofted layer from PBL top to about $3 \mathrm{~km}$ height contributes about 0.1 to the total $532 \mathrm{~nm}$ AOD, which explains the found bias between the AERONET and SÆMS extinction values in Fig. 5 (bottom panel).

The scatter in the SÆMS-derived Angström exponents in Fig. 7 (full range of determined values for the 04:0016:00 UTC period is given as a bar) originate from the measurement uncertainties introduced by the temporally subsequent reference- and measurement-tower observations, which has a much more sensitive influence on the 


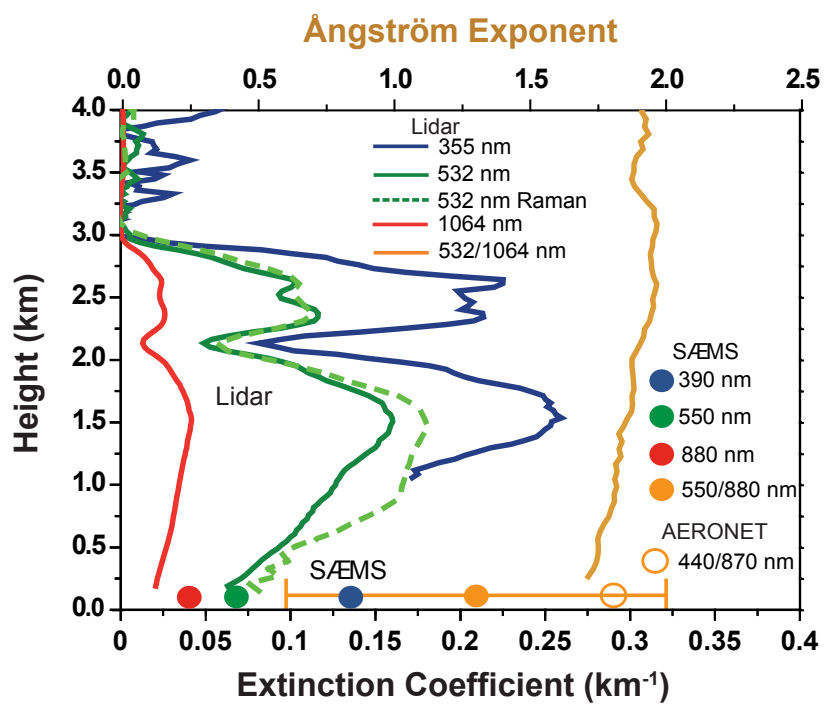

Fig. 7. Vertical profiles of the particle extinction coefficient at 355, 532, and $1064 \mathrm{~nm}$ wavelength and corresponding Ångström exponent (orange, 532-1064 nm spectral range) derived from cloudscreened lidar observations on 3 May 2009, 11:00-13:00 UTC. The circles at ground level are the corresponding SÆMS measurements of the extinction coefficient at $390 \mathrm{~nm}$ (blue circle), $550 \mathrm{~nm}$ (green circle), and $880 \mathrm{~nm}$ (red circle) and the Ångström exponent computed from the extinction values from 550 to $880 \mathrm{~nm}$ (orange circle with uncertainty bar), and from AERONET data (open orange circle, $440-870 \mathrm{~nm}$ ). The elastic backscatter signals are used in the calculation of the extinction coefficient profiles, except for the dashed green line, which is computed from the height profile of the ratio of the elastic $(532 \mathrm{~nm})$ backscatter to nitrogen Raman signal profile, and is almost not overlap-affected.

determination of the spectral slope of the particle extinction coefficient than on the $550 \mathrm{~nm}$ particle extinction values, as well as from short-term particle size changes caused by road dust, road construction activities, and other anthropogenic processes that lead to the release of coarse-mode particles.

In Fig. 8, the SÆMS extinction time series are compared with values calculated from in situ observations of the particle size distribution ( $1 \mathrm{~h}$ mean values). In situ particle size distributions of dry particles are measured continuously at TROPOS within the German Ultrafine Aerosol Network (GUAN; Birmili et al., 2009). The combination of a twin differential mobility particle sizer (TDMPS; Birmili et al., 1999), and an aerodynamic particle sizer (APS) provide a wide size distribution between $5 \mathrm{~nm}$ and $10 \mu \mathrm{m}$. These observations are performed at almost the same height level as the SÆMS observations, but at a distance of 300-3000 m west of the SÆMS optical measurement path. The particle extinction coefficient is calculated with a Mie scattering code from the dry particle size distribution and by assuming refractive index values for non-absorbing urban aerosol particles (real part of 1.53). The computed extinction coefficients for dry conditions are then converted into extinction values

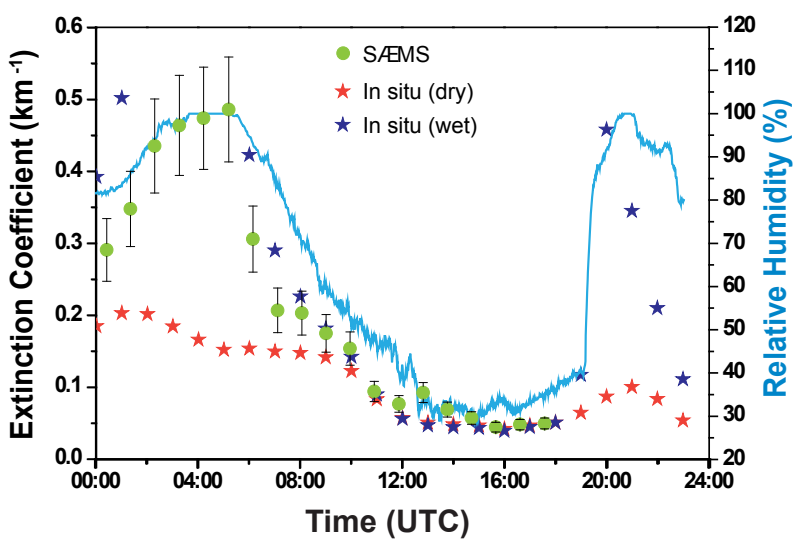

Fig. 8. Time series of the extinction coefficient on 3 May 2009 at $550 \mathrm{~nm}$ (SÆMS, green circles) in comparison to extinction coefficients calculated from in situ aerosol observations on the roof of the TROPOS building. Red stars are computed from in situ-measured dry particle size distribution, and blue stars are computed from the in situ observations after applying a particle-water-uptake correction. A strong correlation of particle extinction and relative humidity (light-blue line) is obvious.

for ambient humidity conditions by using the parameterization for urban aerosol as proposed by Hänel (1984). On 3 May 2009, the relative humidity inside the instruments was approximately $25 \%$.

Good agreement between the humidity-corrected in situ observations and those of the SÆMS are found for the period from 08:00 to 18:00 UTC, especially after 12:00 UTC, when the relative humidity was very low, the atmosphere well mixed, and the aerosol horizontally homogeneous distributed. The good agreement again corroborates the quality of the SÆMS observations. Before 08:00 UTC, strong deviations between the different measurements are given, and can be explained by a potentially wrong humidity correction of the in situ data, horizontal inhomogeneities in the aerosol distribution, and the use of non-appropriate refractive index in the Mie scattering calculations.

Another product of SÆMS is the spectral slope of the particle extinction spectrum. In Fig. 9, the comparison of the spectral extinction coefficient measured with SÆMS, AERONET photometer, and in situ measurements (for dry aerosol particles) is presented. The shown observations are in reasonable agreement. The AERONET Ångström exponent is higher than the SÆMS Angström value because of the probably dominating influence of the fine-mode aerosol in the column (controlled by regional and long-range transport) and the stronger influenced of coarse-mode particles (local aerosols) on the SÆMS observations. The in situ measurements are performed on the roof of the TROPOS building, several hundred meters away from direct aerosol sources like streets. 


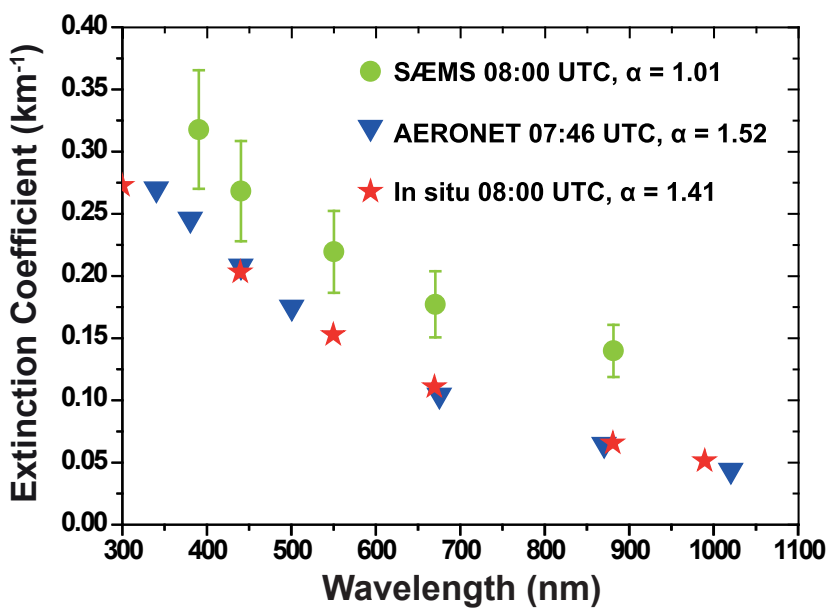

Fig. 9. Spectral particle extinction coefficient measured with SÆMS on the morning of 3 May 2009 (green circles). For comparison, AERONET-derived spectral AOD shown as vertical mean for the $3 \mathrm{~km}$ tropospheric aerosol layer (blue triangles) and extinction coefficients computed from in situ-measured particle size distributions (red stars, dry aerosol particles) are shown. The corresponding Ångström exponents $\alpha(400-900 \mathrm{~nm})$ are also specified.

Figure 10 finally presents the results of the in situmeasured and retrieved volume size distributions derived from the spectral data shown in Fig. 9. The inversion of the spectral data was performed by the algorithm of Müller et al. (1999a, b) and Veselovskii et al. (2002). Discrete spectral extinction values were used as input data.The SÆMS results are the most uncertain ones. It is well known that spectral extinction data alone only allow for a rough estimation of the size distribution. In contrast, the AERONET size distribution retrieval is based on spectral AOD observations as well as on measurements of the particle-scattering phase function. These results are much more accurate, but are representative of the vertical column, and thus dominated by fine-mode particles as discussed above. Under the rough assumption of a homogeneous aerosol layer of $3 \mathrm{~km}$ height the columnar size distribution was converted into volume size distribution.

All three approaches show the bimodal size distribution. A good agreement is found between the in situ and the SÆMS observations concerning the fine-mode particles. AERONET column observations fit well with SÆMS in the case of the fine mode and the coarse mode. The comparably low ratio of fine-mode to coarse-mode particle volume concentration in the case of SÆMS may again be caused by the strong impact of coarse soil dust along the measurement path of $30-50 \mathrm{~m}$ above streets, construction areas, and sites of industrial activities.

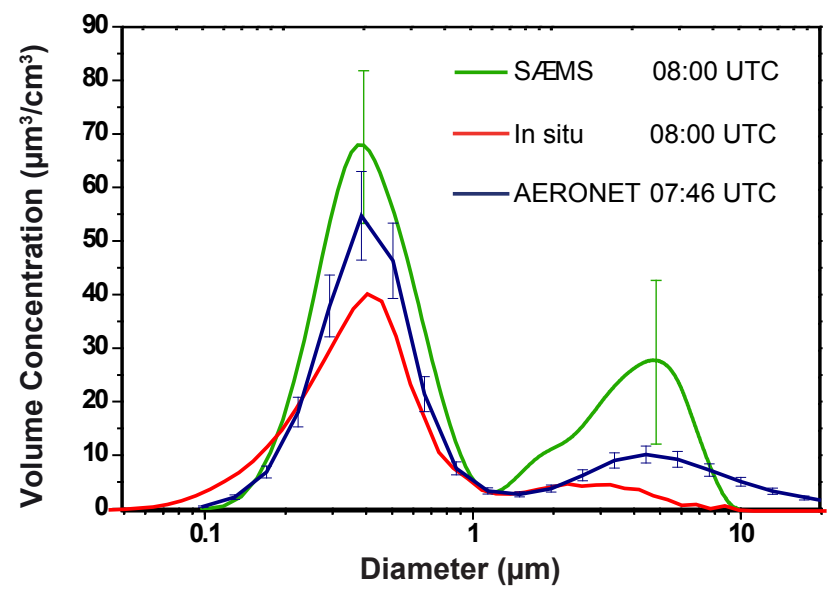

Fig. 10. Particle volume size distribution $\left(\mathrm{d} V / \mathrm{d} \log D_{\mathrm{p}}\right)$ derived from SÆMS extinction spectra, from AERONET data (assuming a height of the tropospheric aerosol column of $3 \mathrm{~km}$ ), and from the in situ observations. Colors are the same as in Fig. 9.

\subsection{Statistics}

The long-term monitoring potential is another unique feature of SÆMS. An overview of the statistical distributions of the particle extinction coefficients and Ångström exponents observed in the year of 2009 is given in Figs. 11 and 12 . About $30 \%$ of the year 2009 were covered by SÆMS measurements, i.e., 5314 half-hour extinction values are considered in Fig. 11. For all 2009 AERONET AOD values the PBL height was determined, from available ceilometer or lidar observations or from numerical weather forecast data (GDAS: global data assimilation system, http://www.arl.noaa.gov/gdas.php) (Kanamitsu, 1989) to determine the shown estimated mean PBL extinction coefficients. The agreement between the SÆMS and the AERONET frequency distributions is good, keeping in mind that SÆMS measurements are strongly influenced by locally produced aerosol particles, whereas the AERONET values show the influence of regional to long-range transport on aerosol particles, and are widely dominated by impact of lofted fine-mode aerosol. The comparison of SÆMS results with the extinction values derived from the in situmeasured size distribution of dry aerosol particles nicely shows the influence of ambient humidity conditions on the particle extinction. The mode extinction values of the fitted curves are $0.09 \mathrm{~km}^{-1}$ (SÆMS), $0.075 \mathrm{~km}^{-1}$ (AERONET), and $0.03 \mathrm{~km}^{-1}$ (in situ).

The comparison of the AERONET and SÆMS Ångström exponents reveals a relatively narrow AERONET spectrum with $80 \%$ of the values in the interval from 1.1 to 1.8 , which clearly indicates the dominance of fine-mode aerosol in the vertical column over Leipzig throughout the year, and a broad SÆMS spectrum that may be strongly influenced by locally emitted coarse-mode particles occurring frequently 


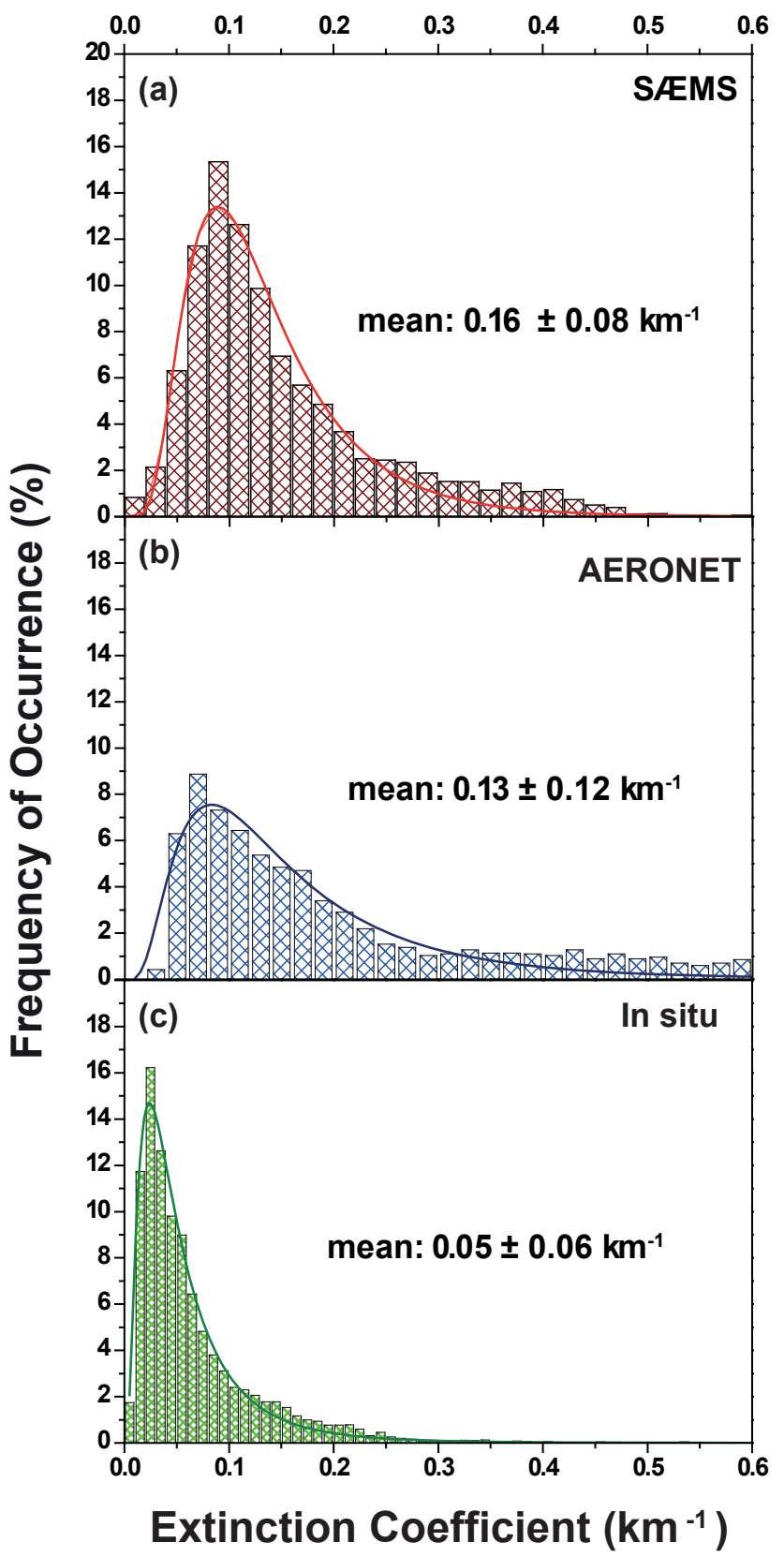

Fig. 11. Frequency distribution of (a) particle extinction coefficients observed with SÆMS at Leipzig in 2009, (b) PBL mean extinction coefficient derived from AERONET observations, and (c) dry particle extinction coefficient, computed from in situ observations of the particle size distribution.

close to the surface. However, about 5-8\% of the SÆMS Ångström values are unrealistically large $(>2.0)$ and $15 \%$ of the values are extremely low $<0.2$, which may indicate the SÆMS retrieval uncertainties in the Ångström exponent determination. Nevertheless, at low height, considerably lower Ångström values prevail because of road dust and dust originating from constructional activities.

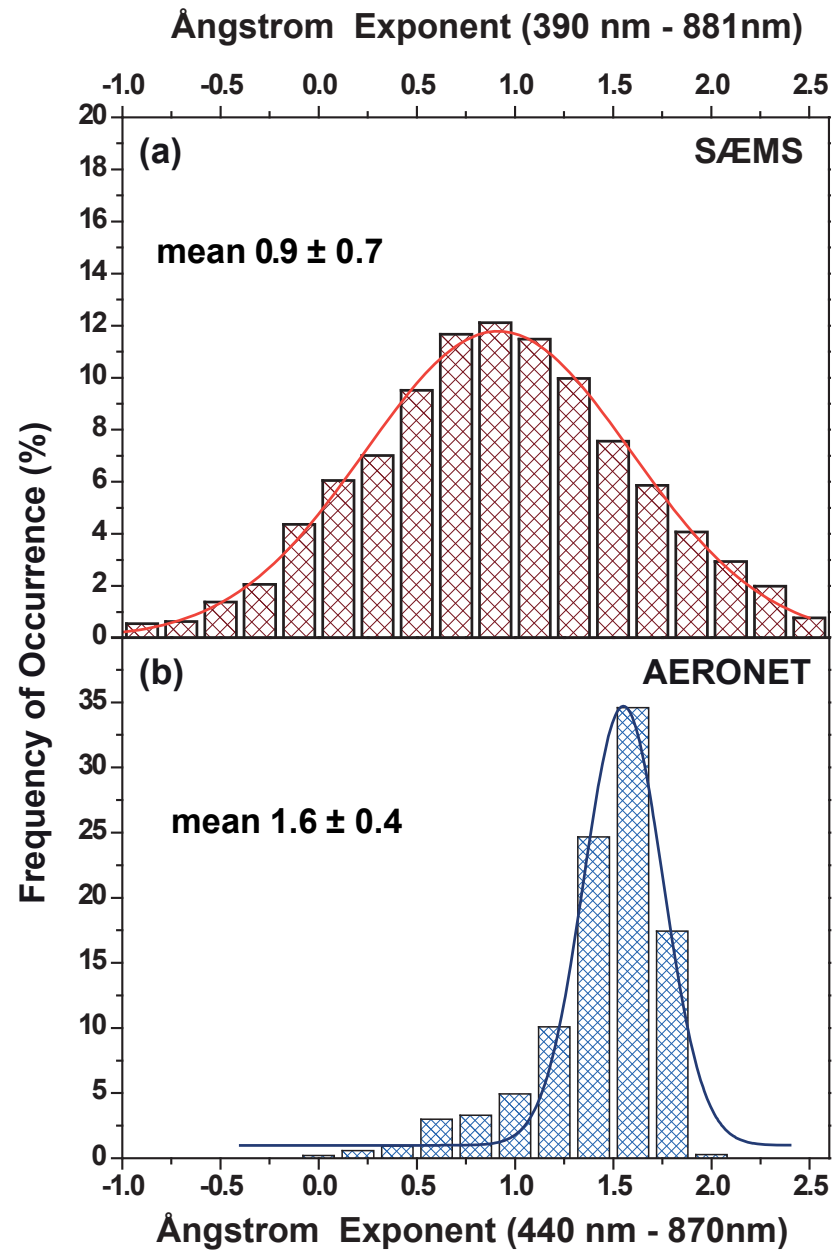

Fig. 12. Frequency distribution of Ångström exponents as observed with (a) SÆMS at 30-50 m height above ground in 2009 and (b) with an AERONET photometer in the vertical column in 2009.

\section{Conclusions}

The Spectral Aerosol Extinction Monitoring System (SÆMS) was described which is able to continuously measure particle extinction spectra at ambient conditions around the clock and throughout the year. The spectral extinction coefficient of atmospheric aerosol particles is measured along an approximately $5.7 \mathrm{~km}$ long optical path at $30-50 \mathrm{~m}$ height above ground at TROPOS, Leipzig. The unique infrastructure at TROPOS allowed us to perform comprehensive comparisons with lidar, photometer, and in situ aerosol observations of aerosol optical and microphysical properties. The statistical analysis and the case study verify good to acceptable agreement between the different measurements and corroborate the potential of SÆMS to provide trustworthy particle extinction spectra as time series.

In the next step we will focus on the analysis of our long-term observation performed since 2009 , with emphasis on the relationship between particle extinction and relative 
humidity. The new aspect here is to concentrate on particle extinction measurements up to $>95 \%$ relative humidity. In the future, we will also implement a water vapor spectrometer to accurately determine the absolute water vapor concentration and, by combing these water vapor measurements with the temperature measurements, improve the quality of relative humidity measurements, especially at very high relative humidities.

Acknowledgements. We thank the Deutsche Forschungsgemeinschaft for funding under grant HE939/30-1. In situ particle size distributions at Leipzig-TROPOS were provided by Wolfram Birmili and Kay Weinhold. These measurements within the German Ultrafine Aerosol Network (GUAN) were supported by the German Federal Environment Ministry (BMU) grant F\&E 370343200 (German title: Erfassung der Zahl feiner und ultrafeiner Partikel in der Außenluft). We also thank K. Flachowsky and R. Dubois for providing the meteorological data.

Edited by: V. Amiridis

\section{References}

Ångström, A.: The Parameters of Atmospheric Turbidity, Tellus, 595, 64-75, 1964.

Ansmann, A.: Ground-truth aerosol lidar observations: can the Klett solutions obtained from ground and space be equal for the same aerosol case?, Appl. Optics, 45, 3367-3371, 2006.

Baars, H., Ansmann, A., Engelmann, R., and Althausen, D.: Continuous monitoring of the boundary-layer top with lidar, Atmos. Chem. Phys., 8, 7281-7296, doi:10.5194/acp-8-7281-2008, 2008

Birmili, W., Stratmann, F., and Wiedensohler, A.: Design of a DMA-based size spectrometer for a large particle size range and stable operation, Aerosol Sci., 30, 549-553, 1999.

Birmili, W., Weinhold, K., Nordmann, S., Wiedensohler, A., Spindler, G., Müller, K., Herrmann, H., Gnauk, T., Pitz, M., Cyrys, J., Flentje, H., Nickel, C., Kuhlbusch, T., Löschau, G., Haase, D., Meinhardt, F., Schwerin, A., Ries, L., and Wirtz, K.: Atmospheric aerosol measurements in the German Ultrafine Aerosol Network (GUAN): Part 1 - soot and particle number size distributions, Gefahrst. Reinh. Luft, 69, 137-145, 2009.

Bucholtz, A.: Rayleigh-scattering calculations for the terrestrial atmosphere, Appl. Optics, 34, 2765-2773, 1995.

Bundke, U., Hänel, G., Horvath, H., Kaller, W., Seidl, S., Wex, H., Wiedensohler, A., Wiegner, M., and Freudenthaler, V.: Aerosol optical properties during the Lindenberg Aerosol Characterization Experiment (LACE 98), J. Geophys. Res., 107, 8123, doi:10.1029/2000JD000188, 2002.

Carrico, C. M., Rood, M. J., and Ogren, J. A.: Aerosol light scattering properties at Cape Grim, Tasmania, during the first Aerosol Characterization Experiment (ACE 1), J. Geophys. Res., 103, 16565-16574, doi:10.1029/98JD00685, 1998.

Carrico, C. M., Rood, M. J., Ogren, J. A., Neusüß, C., Wiedensohler, A., and Heintzenberg, J.: Aerosol Optical properties at Sagres, Portugal during ACE-2, Tellus B, 52, 694-715, doi:10.1034/j.1600-0889.2000.00049.x, 2000.
Draxler, R. and Rolph, G.: HYSPLIT (HYbrid Single-Particle Lagrangian Integrated Trajectory) Model access via NOAA ARL READY Website, available at: http://ready.arl.noaa.gov/ HYSPLIT.php (last access: 19 February 2014), 2011.

Fierz-Schmidhauser, R., Zieger, P., Vaishya, A., Monahan, C., Bialek, J., O’Dowd, C. D., Jennings, S. G., Baltensperger, U., and Weingartner, E.: Light scattering enhancement factors in the marine boundary layer (Mace Head, Ireland), J. Geophys. Res., 115, D20204, doi:10.1029/2009jd013755, 2010.

Fitzgerald, J., Hoppel, W., and Vietti, M.: The size and scattering coefficient of urban aerosol particles at Washington, DC as a function of relative humidity, J. Atmos. Sci., 39, 1838-1852, 1982.

Flentje, H., Dubois, R., Heintzenberg, J., and Karbach, H.-J.: Retrieval of aerosol properties from boundary layer extinction measurements with a DOAS system, Geophys. Res. Lett., 24, 2019 2022, 1997.

Gasso, S., Hegg, D. A., Covert, D. S., Collins, D., Noone, K. J., Ostrom, E., Schmid, B., Russell, P. B., Livingston, J. M., Durkee, P. A., and Jonsson, H.: Influence of humidity on the aerosol scattering coefficient and its effect on the upwelling radiance during ACE-2, Tellus B, 52, 546-567, 2000.

Hänel, G.: Aerosol Particles as Functions of the Relative Humidity at Thermodynamic Equilibrium with the Surrounding Moist Air, Vol. 19, Chap. 2, 74-189, Academic Press, New York, London, 1976.

Hänel, G.: Parametrization of the Influence of Relative Humidity on Optical Aerosol Properties, A. Deepak, Hampton, Virginia, 117-122, 1984.

Kanamitsu, M.: Description of the NMC global data assimilation and forecast system, Weather Forecast, 4, 335-342, 1989.

Koren, I., Remer, L. A., Kaufman, Y. J., Rudich, Y., and Martins, J. V.: On the twilight zone between clouds and aerosols, Geophys. Res. Lett., 34, L08805, doi:10.1029/2007GL029253, 2007.

Koren, I., Feingold, G., Jiang, H., and Altaratz, O.: Aerosol effects on the inter-cloud region of a small cumulus cloud field, Geophys. Res. Lett., 36, L14805, doi:10.1029/2009GL037424, 2009.

Koschmieder, H.: Theorie der horizontalen Sichtweite, Beitr. Phys. Freie Atmos., 12, 33-53 and 171-181, 1924.

Lee, J., Kim, Y., Kuk, B., Geyer, A., and Platt, U.: Simultaneous Measurements of Atmospheric Pollutants and Visibility with a Long-Path DOAS System in Urban Areas, Environ. Monit. Assess., 104, 281-293, 2005.

McInnes, L., Bergin, M., Ogren, J., and Schwartz, S.: Apportionment of light scattering and hygroscopic growth to aerosol composition, Geophys. Res. Lett., 25, 513-516, doi:10.1029/98g100127, 1998.

Müller, T.: Bestimmung streckenintegrierter Aerosolparameter und Wasserdampfkonzentrationen aus spektralen Extinktionsmessungen, Dissertation, University of Leipzig, Germany, 2001.

Müller, D., Wandinger, U., and Ansmann, A.: Microphysical Particle Parameters from Extinction and Backscatter Lidar Data by Inversion with Regularization: Theory, Appl. Optics, 38, 23462357, 1999a.

Müller, D., Wandinger, U., and Ansmann, A.: Microphysical Particle Parameters from Extinction and Backscatter Lidar Data by Inversion With Regularization: Simulation, Appl. Optics, 38, 2358-2368, 1999b. 
Müller, T., Müller, D., and Dubois, R.: Particle extinction measured at ambient conditions with differential optical absorption spectroscopy. 1. System setup and characterization, Appl. Optics, 44, 1657-1666, 2005.

Platt, U.: Differential Optical Absorption Spectroscopy (DOAS), Wiley \& Sons, New York, 1994.

Platt, U. and Perner, D.: Measurements of atmospheric trace gases by long path differential UV/visible absorption spectroscopy, 97105, Springer-Verlag, Berlin, 1983.

Veselovskii, I., Kolgotin, A., Griaznov, V., Müller, D., Wandinger, U., and Whiteman, D. N.: Inversion With Regularization for the Retrieval of Tropospheric Aerosol Parameters From Multiwavelength Lidar Sounding, Appl. Optics, 41, 3685-3699, 2002.
Zieger, P., Weingartner, E., Henzing, J., Moerman, M., de Leeuw, G., Mikkilä, J., Ehn, M., Petäjä, T., Clémer, K., van Roozendael, M., Yilmaz, S., Frieß, U., Irie, H., Wagner, T., Shaiganfar, R., Beirle, S., Apituley, A., Wilson, K., and Baltensperger, U.: Comparison of ambient aerosol extinction coefficients obtained from in-situ, MAX-DOAS and LIDAR measurements at Cabauw, Atmos. Chem. Phys., 11, 2603-2624, doi:10.5194/acp11-2603-2011, 2011.

Zieger, P., Fierz-Schmidhauser, R., Weingartner, E., and Baltensperger, U.: Effects of relative humidity on aerosol light scattering: results from different European sites, Atmos. Chem. Phys., 13, 10609-10631, doi:10.5194/acp-13-10609-2013, 2013. 